\title{
HUBUNGAN TOPOGRAFI LAHAN DAN TINGGI POHON DENGAN KELELAHAN PEKERJA DAN PRODUKTIVITAS PEMANENAN KELAPA SAWIT
}

\section{CORRELATION BETWEEN TOPOGRAPHY AND HEIGHT OF TREE WITH FATIGUE OF WORKER AND PRODUCTIVITY OF PALM OIL HARVESTING}

\author{
Mizi Adha Visano*, Meizul Zuki dan Damres Uker \\ Jurusan Teknologi Pertanian, Fakultas Pertanian Universitas Bengkulu \\ *Email korespondensi: miziadha@gmail.com \\ Diterima 17-09-2020, diperbaiki 22-10-2020, disetujui 15-11-2020
}

\begin{abstract}
The purpose of this research was to analyze the correlation between topography with fatigue of worker, height of tree with fatigue of worker, topography and height of tree with fatigue of worker and fatigue of worker with productivity of palm oil harvesting. The analytical method used in this research was the analysis of correlation and linear regression. Based on the results of this study concluded that there was a weak correlation $(r=0,214)$, but significant and in the same direction (positive) between topography with fatigue of palm oil harvester by linear regression equation $\hat{Y}_{1}=$ $3,037+0,067 X_{1}$, there was a sufficient strong correlation $(r=0,501)$, but significant and in the same direction (positive) between height of tree with fatigue of palm oil harvester by linear regression equation $\hat{Y}_{1}=0,307+0,408 X_{2}$, there was a sufficient strong $(R=0,598)$ and significant correlation between topography and height of tree with fatigue of palm oil harvester by linear regression equation $\hat{Y}_{1}=-1,383+0,104 X_{1}+0,466 X_{2}$, and there was a weak correlation $(r=-0,373)$, but significant and not in the same direction (negative) between fatigue with work productivity of palm oil harvester by linear regression equation $\hat{Y}_{2}=379,243-23,495 X$.
\end{abstract}

Keywords: Harvesting, topography, height of tree, fatigue, productivity

\begin{abstract}
ABSTRAK
Tujuan dalam penelitian ini adalah untuk menganalisis hubungan antara topografi lahan dengan kelelahan pekerja, tinggi pohon dengan kelelahan pekerja, topografi lahan dan tinggi pohon dengan kelelahan pekerja serta kelelahan pekerja dengan produktivitas pemanenan kelapa sawit. Metode analisis yang digunakan dalam penelitian ini adalah analisis korelasi dan regresi linier. Bedasarkan hasil penelitian dapat disimpulkan bahwa terdapat hubungan yang lemah $(r=0,214)$, namun signifikan dan searah (positif) antara faktor topografi lahan dengan kelelahan pekerja panen kelapa sawit dengan persamaan regresi linier $\widehat{Y}_{1}=3,037+0,067 \mathrm{X}_{1}$, terdapat hubungan yang cukup kuat $(r=$ 0,501 ), namun signifikan dan searah (positif) antara tinggi pohon dengan kelelahan pekerja panen kelapa sawit dengan persamaan regresi linier $\hat{Y}_{1}=0,307+0,408 \mathrm{X}_{2}$, terdapat hubungan yang cukup kuat $(R=0,598)$ dan signifikan antara topografi lahan dan tinggi pohon dengan kelelahan pekerja panen kelapa sawit dengan persamaan regresi linier $\hat{Y}_{1}=-1,383+0,104 \mathrm{X}_{1}+0,466 \mathrm{X}_{2}$ serta terdapat hubungan yang lemah $(r=-0,373)$, namun signifikan dan tidak searah (negatif) antara kelelahan
\end{abstract}


pekerja dengan produktivitas pemanenan kelapa sawit dengan persamaan regresi linier $\widehat{Y}_{2}=379,243$ $23,495 \mathrm{X}$.

Kata Kunci: Pemanenan, topografi, tinggi pohon, kelelahan, produktivitas

\section{PENDAHULUAN}

Pemanenan kelapa sawit merupakan salah satu kegiatan yang penting pada pengelolaan tanaman kelapa sawit. Proses pemanenan kelapa sawit meliputi memotong pelepah bagian bawah kelapa sawit, merapikan pelepah yang telah dipotong, memotong tandan buah sawit yang telah matang, mengangkut tandan buah sawit ke tempat pemungutan hasil dan akhirnya mengutip brondolan yang jatuh saat proses pemanenan. Seluruh proses pemanenan tersebut dilakukan secara manual oleh pekerja panen kelapa sawit. Pemanen kelapa sawit akan menentukan suksesnya kegiatan ini. Kelapa sawit (Elais Guineensis Jacq) merupakan salah satu komoditas perkebunan yang memiliki peran penting dalam menghasilkan devisa negara melalui minyak sawit dan minyak inti sawit. Luas areal tanaman kelapa sawit Provinsi Bengkulu sebesar 191.267 $\mathrm{Ha}$ (BPS Provinsi Bengkulu, 2016). Kondisi topografi merupakan salah satu pertimbangan dalam menentukan jumlah tenaga kerja pemanen.

Topografi lahan kebun kelapa sawit terdiri dari beberapa jenis, yaitu datar, miring dan sangat miring. Semakin tidak datarnya lahan maka semakin sulit kegiatan pemanenannya. Untuk areal berbukit pada umumnya kondisi medan kebun lebih berat bagi pemanen untuk melakukan pergerakan karena kondisi tanah yang labil dan adanya tanjakan dan turunan. Pemanen harus meyesuaikan cara kerja pemanenan sesuai dengan kondisi topografi lahan pemanenan. Tingkat kesulitan areal (topografi) sangat mempengaruhi tingkat losses produksi (Nurzam dkk, 2014). Menurut Santosa dan Andreas (2014) kondisi topografi perkebunan kelapa sawit yang beragam menjadi permasalahan tersendiri dalam pengelolaan panen kelapa sawit.
Beragamnya lahan pengusahaan kelapa sawit menyebabkan keberagaman produktivitas kelapa sawit. Produksi yang sangat baik diperoleh jika kelerengan kurang dari 11,65 \% (Mimboro dkk, 2015). Selain kondisi topografi lahan kebun kelapa sawit, tinggi pohon kelapa sawit juga berpotensi menimbulkan permasalahan dalam pemanenan.

Menurut Mentari dkk (2012) cara kerja panen antara tanaman kelapa sawit yang berbeda ketinggian memiliki tingkat kesulitan yang berbeda dalam pengerjaannya. Pemanenan dengan tinggi pohon 2-5 meter cenderung lebih mudah dan menggunakan peralatan tidak seberat peralatan untuk pemanenan dengan tinggi pohon lebih dari 5 meter.

Kesulitan-kesulitan dalam kegiatan panen kelapa sawit seperti pohon kelapa sawit yang cukup tinggi dan lahan yang tidak datar dapat menyebabkan kelelahan kerja yang dialami pemanen. Lingkungan kerja pemanenan kelapa sawit menjadi beban kerja tambahan bagi pemanen kelapa sawit. Beban kerja yang terlalu berat menimbulkan kelelahan.

Menurut Tarwaka dkk (2004) istilah kelelahan biasanya menunjukan kondisi yang berbeda-beda dari setiap individu, tetapi semuanya bermuara kepada kehilangan efisiensi dan penurunan kapasitas kerja serta ketahanan tubuh. Kelelahan kerja dapat mengurangi kinerja dan produktivitas di tempat kerja (Chesnal dkk, 2014). Menurut Muizzudin (2013) apabila tenaga kerja mengalami kelelahan kerja, maka akibat yang akan ditimbulkannya akan dirasakan oleh perusahaan berupa penurunan produktivitas perusahaan. Menurut Nainggolan dkk (2012) produktivitas perusahaan kelapa sawit sangat tergantung pada produktivitas kerja dari pemanen kelapa sawit itu sendiri. 
Sangat jarang peneliti menyoroti hubungan faktor lingkungan kerja dengan kelelahan pekerja khususnya pada pemanenan kelapa sawit. Dari hasil survei pendahuluan, baik para staf afdeling maupun pemanen menyatakan bahwa lingkungan kerja pemanenan kelapa sawit seperti topografi lahan dan tinggi pohon dapat dikatakan menjadi sebagian penyebab daripada kelelahan yang dialami para pemanen kelapa sawit.

Berdasarkan uraian di atas maka penelitian ditujukan untuk menganalisis hubungan antara topografi lahan dengan kelelahan pekerja, hubungan antara tinggi pohon dengan kelelahan pekerja, hubungan antara topografi lahan dan tinggi pohon dengan kelelahan pekerja serta hubungan antara kelelahan pekerja dengan produktivitas pemanenan kelapa sawit.

\section{METODE PENELITIAN}

\section{Alat Penelitian}

Alat yang digunakan dalam pelaksanaan penelitian ini adalah alat tulis kantor (ATK), kamera, kuisioner, meteran, klinometer Suunto Type PM-5/360 PC, program Ms.Office Excel 2007 dan program SPSS Statistics 17.0.

\section{Populasi dan Sampel Penelitian Populasi Penelitian}

Populasi dalam penelitian ini merupakan pemanen kelapa sawit di Afdeling 1-3 PT. Bio Nusantara Teknologi, Pondok Kelapa, Bengkulu Tengah. Total keseluruhan pemanen adalah 60 orang dengan total 441 hancak panen.

\section{Sampel Penelitian}

Teknik pengambilan sampel menggunakan purposive sampling yaitu pemilihan dengan pertimbangan atau kriteria tertentu.

Sampel penelitian berjumlah 10 orang dengan 67 hancak panen. Kriteria pemilihan sampel adalah sebagai berikut :

a. Pemanen yang berumur 31-40 tahun b. Pemanen dengan pengalaman kerja 815 tahun.

c. Kegiatan pemanenan dimulai dari persiapan alat panen di lahan panen, memotong pelepah dan TBS dari pohon kelapa sawit, merapikan pelepah kelapa sawit yang telah dipotong serta mengumpulkan TBS yang ditelah dipanen di satu tempat. Kegiatan panen yang diamati adalah kegiatan panen pada saat cuaca tidak hujan.

\section{Variabel Pengamatan}

Mengacu pada paradigma penelitian ada 4 (empat) variabel pengamatan dalam penelitian ini yaitu :

\section{Topografi Lahan}

Topografi lahan yang diamati saat panen yaitu lahan dengan derajat kemiring an kurang dari $8^{0}$, lahan miring dengan derajat kemiringan $8^{0}-14^{0}$ dan lahan sangat miring dengan derajat kemiringan lebih dari $14^{0}$.

\section{Tinggi Pohon}

Tinggi pohon yang dimaksudkan adalah tinggi pohon kelapa sawit tanaman menghasilkan dan dikelompokkan menjadi 3 kelompok tinggi pohon, yaitu 2-6 m, 7-9 $\mathrm{m}$ dan 10-12 $\mathrm{m}$ diukur dari permukaan tanah sampai letak tandan buah yang akan dipanen.

\section{Kelelahan Pekerja}

Data kelelahan pekerja dikumpulkan menggunakan kuisioner dari Industrial Fatique Research dengan fokus pada kelelahan fisik, maka yang digunakan hanya 10 pertanyaan tentang gambaran kelelahan fisik dengan jawaban pertanyaan ya (1) atau tidak (0).

\section{Produktivitas}

Dalam penelitian ini produktivitas pemanen kelapa sawit didapat dengan menghitung jumlah hasil panen $(\mathrm{Kg})$ dibagi jumlah jam kerja sehari (jam). 


\section{Tahapan Penelitian}

Menganalisis Hubungan antara Topografi Lahan dengan Kelahan Pekerja

Untuk mencapai tujuan penelitian tersebut, maka data yang diperlukan yaitu data topografi lahan (derajat kemiringan) dan data skor kelelahan pekerja.

\section{Menganalisis Hubungan antara Tinggi Pohon dengan Kelelahan Pekerja}

Untuk mencapai tujuan penelitian tersebut, maka data yang diperlukan yaitu data tinggi pohon (meter) dan data skor kelelahan pekerja.

\section{Menganalisis Hubungan Topograf $i$ Lahan dan Tinggi Pohon dengan Kelelahan Pekerja}

Untuk mencapai tujuan penelitian tersebut, maka data yang diperlukan yaitu data topografi lahan dan data skor kelelahan pekerja.

Menganalisis Hubungan antara Kelelahan Pekerja dengan Produktivitas.

Untuk mencapai tujuan penelitian tersebut, maka data yang diperlukan yaitu data skor kelelahan pekerja dan data produktivitas $(\mathrm{kg} / \mathrm{jam})$.

\section{Pengumpulan Data}

Data yang dikumpulkan dalam penelitian ini berupa data primer dan data sekunder, yaitu : topografi lahan (derajat kemiringan), tinggi pohon, skor kelelahan pekerja dan produktivitas kerja.

\section{Analisis Data}

Metode analisis yang digunakan dalam penelitian ini adalah analisis korelasi dan regresi linier. Perangkat lunak analisis adalah program SPSS Statistics 17.0.

Penentuan kekuatan hubungan antar variabel penelitian berpedoman pada ketentuan yang disampaikan oleh Sugiyono (2010) disajikan pada Tabel 1.
Tabel 1. Pedoman untuk memberi interpretasi koefisien korelasi.

\begin{tabular}{ll}
\hline Interval Koefisien & Tingkat Hubungan \\
\hline $0,00-0,199$ & sangat lemah \\
$0,20-0,399$ & lemah \\
$0,40-0,599$ & sedang/cukup kuat \\
$0,60-0,799$ & kuat \\
$0,80-1,000$ & sangat kuat \\
\hline
\end{tabular}

\section{HASIL DAN PEMBAHASAN}

\section{Hubungan antara Topografi Lahan dengan Kelelahan Pekerja}

Hasil analisis korelasi sederhana dan regresi linier sederhana hubungan antara topografi lahan dengan kelelahan pekerja dapat dilihat pada Tabel 2 dan Tabel 3 :

Tabel 2. Hasil Analisis Korelasi Hubungan antara Topografi Lahan dengan Kelelahan Pekerja.

\begin{tabular}{ccc}
\hline \multicolumn{2}{c}{ Nilai } & Keterangan \\
\hline $\mathrm{r}$ & 0,214 & $\begin{array}{c}\text { Korelasi lemah } \\
\text { dan searah }\end{array}$ \\
Signifikansi & $<0,05$ & $\mathrm{H}_{0}$ ditolak \\
\hline \multicolumn{2}{l}{ Sumber : data diolah }
\end{tabular}

Tabel 3. Hasil Analisis Regresi Linier Hubungan antara Topografi Lahan dengan Kelelahan Pekerja.

\begin{tabular}{ccc}
\hline \multicolumn{2}{c}{ Nilai } & Persamaan \\
\hline$\alpha$ & 3,037 & $\hat{Y}_{1}=3,037+0,067 \mathrm{X}_{1}$ \\
$\beta$ & 0,067 &
\end{tabular}

Sumber : data diolah

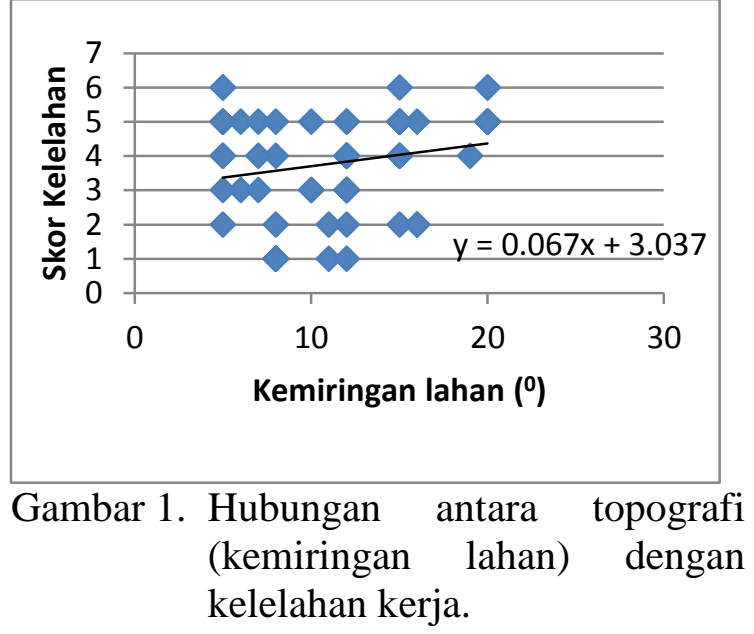


Topografi lahan merupakan bagian dari lingkungan kerja pemanenan kelapa sawit. Lingkungan kerja dapat memberikan beban tambahan kepada pekerja (Tarwaka dkk, 2004). Sehingga dapat dikatakan topografi lahan adalah bagian dari beban kerja pemanen kelapa sawit. Hubungan antara topografi lahan dengan kelelahan pekerja mempunyai korelasi yang lemah, karena nilai $r=0,214$ berada dalam interval 0,20 - 0,399 (Sugiyono, 2010). Sejalan dengan Nurjannah (2014) dalam penelitian yang berjudul "Hubungan antara Beban Kerja dengan Kelelahan Kerja pada Karyawan Bagian Cutting PT. Dan Liris Banaran Kabupaten Sukoharjo" terdapat hubungan yang sangat rendah antara beban kerja dengan kelelahan kerja. Hasil analisis korelasi bernilai positif maka diketahui bahwa hubungan antara lahan dengan kelelahan pekerja adalah searah. Hal ini berarti apabila topografi lahan tinggi, maka kelelahan pekerja juga tinggi.

Terdapat hubungan yang signifikan antara topografi lahan dengan kelelahan pekerja dengan nilai signifikansi lebih kecil dari nilai probabilitas $(0,05)$. Menurut Oesman dan Risma (2011) dalam penelitiannya yang berjudul "Hubungan Faktor Internal dan Eksternal Terhadap Kelelahan Kerja Melalui Subjective Self Rating Test" ada hubungan yang signifikan untuk faktor ekternal (beban kerja) terhadap terjadinya kelelahan.

Responden dalam penelitian mengatakan bahwa memanen kelapa sawit pada lahan sangat miring jauh lebih lelah dibanding memanen pada lahan datar. Mereka berpendapat bahwa tingkat kesulitan di lahan sangat miring jauh lebih besar dibandingkan tingkat kesulitan di lahan datar. Responden juga menyatakan bahwa tenaga yang dibutuhkan saat memanen di lahan sangat miring jauh lebih besar dibandingkan saat memanen di lahan miring dan datar. Hal tersebut sejalan dengan pernyataan Santosa dan Andreas (2014) dalam penelitian dengan judul "Pengaruh Topografi Lahan dan Umur Pemanen Terhadap Kapasitas Kerja
Pemanenan Kelapa Sawit" yang menyatakan bahwa pemanenan lebih sulit di lahan dengan kemiringan besar. Dimana kesulitan pemanenan kelapa sawit dapat menyebabkan kelelahan fisik. Semakin sulit kondisi lahan maka semakit tinggi kelelahan yang dialami oleh pekerja panen kelapa sawit. Putranti, et al. (2012) dalam penelitian yang berjudul "Studi Waktu (Time Study) pada Aktivitas Pemanenan Kelapa Sawit di Perkebunan Sari Lembah Subur, Riau" menyatakan bahwa kesulitan memanen pada topografi datar dapat dikatakan 0 (nol) dan waktu baku memanen pada topografi datar juga lebih cepat dibandingkan pada topografi teras.

Sebelum melakukan kegiatan panen kelapa sawit, para pekerja panen harus menyesuaikan posisi sesuai dengan keadaan lahan. Persiapan posisi pada lahan datar sangat singkat. Pemanen hanya perlu menyesuaikan alat panen agar tepat pada posisi yang diharapkan. Namun pada kondisi lahan miring dan sangat miring, pekerja panen membutuhkan waktu lebih lama karena harus mempertimbangkan posisi berdiri dengan kemungkinan posisi jatuhnya buah (TBS) dan pelepah kelapa sawit. Jika tidak dipertimbangkan dengan baik akan besar kemungkinan pekerja panen mengalami kecelakaan kerja seperti tertimpa buah atau pelepah kelapa sawit. Kondisi lahan juga dapat menambah kesulitan pemanen dalam hal mengumpulkan buah (TBS) yang telah dipanen. Lingkungan yang kurang nyaman dalam bekerja menyebabkan kelelahan kerja. Sehingga semakin sulit lahan dengan derajat kemiringan lebih besar maka semakin tinggi kelelahan pekerja panen kelapa sawit. Lahan yang sangat miring sangat menyulitkan pemanen untuk mengumpulkan buah. Tidak jarang buah yang tidak terjangkau akan tertinggal di lahan dan menjadi losses produksi. Seperti yang dikatakan Nurzam dkk (2014) bahwa tingkat kesulitan areal (topografi) sangat mempengaruhi tingkat losses produksi. Semakin sulit lahan maka akan semakin tinggi tingkat losses produksi. 
Persamaan regresi linier untuk hubungan antara topografi lahan dengan kelelahan pekerja adalah $\hat{Y}_{1}=3,037+0,067$ $\mathrm{X}_{1}$.

\section{Hubungan antara Tinggi Pohon dengan Kelelahan Pekerja}

Hasil analisis korelasi sederhana dan regresi linier sederhana hubungan antara tinggi pohon dengan kelelahan pekerja dapat dilihat pada Tabel 4 dan Tabel 5 :

Tabel 4. Hasil Analisis Korelasi Hubungan antara Tinggi Pohon dengan Kelelahan Pekerja.

\begin{tabular}{ccc}
\hline \multicolumn{2}{c}{ Nilai } & Keterangan \\
\hline $\mathrm{r}$ & 0,501 & $\begin{array}{c}\text { Korelasi cukup kuat } \\
\text { dan searah }\end{array}$ \\
Signifikansi & $<0,05$ & $\mathrm{H}_{0}$ ditolak \\
\hline
\end{tabular}

Sumber : data diolah

Tabel 5. Hasil Analisis Regresi Linier Hubungan antara Tinggi Pohon dengan Kelelahan Pekerja.

\begin{tabular}{crc}
\hline & Nilai & Persamaan \\
\hline$\alpha$ & 0,307 & $\hat{Y}_{1}=0,307+0,408 \mathrm{X}_{2}$ \\
$\beta$ & 0,408 & \\
\hline Sumber : data diolah &
\end{tabular}

Sumber : data diolah

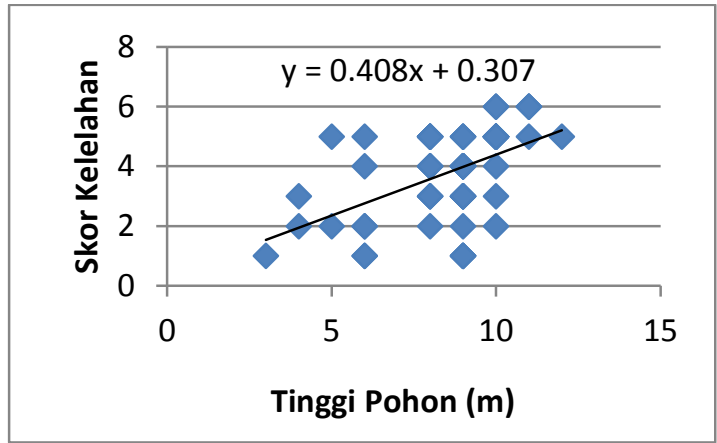

Gambar 2. Hubungan antara tinggi pohon dengan kelelahan kerja.

Hubungan antara tinggi pohon dengan kelelahan pekerja mempunyai korelasi yang cukup kuat, karena nilai $\mathrm{r}=$ 0,501 berada dalam interval $0,40-0,599$ (Sugiyono, 2010). Nilai $r$ pada tabel hasil analisis korelasi bernilai positif maka diketahui bahwa hubungan antara tinggi pohon dengan kelelahan pekerja adalah searah. Hal ini berarti apabila pohon kelapa sawit tinggi, maka kelelahan pekerja juga tinggi. Terdapat hubungan yang signifikan antara tinggi pohon dengan kelelahan pekerja dengan nilai signifikansi lebih kecil dari nilai probabilitas $(0,05)$.

$$
\text { Pemanen yang melakukan }
$$

pemanenan pada pohon kelapa sawit dengan tinggi pohon 2-6 meter menggunakan dodos dan egrek bergalah satu batang. Dimana panjang satu batang galah adalah \pm 6 meter dengan berat $\pm 3 \mathrm{~kg}$. Pemanen yang melakukan pemanenan kelapa sawit dengan tinggi pohon 7-9 meter menggunakan egrek dengan 1,5 batang galah dan pemanen yang melakukan pemanenan pada pohon kelapa sawit dengan tinggi pohon 10-12 meter menggunakan egrek dengan 2 batang galah. Cara memanen tanaman dengan tinggi pohon 2-6 meter cenderung lebih mudah dan beban kerjanya cukup ringan. Saat memanen pohon kelapa sawit yang tinggi pemanen harus menaikan egrek dengan galah yang cukup panjang dan berat agar sampai ke buah yang akan dipanen. Posisi galah harus dipertimbangkan dengan baik agar tidak menyebabkan resiko tertimpa buah atau pelepah. Pemanen juga cenderung terpaksa menengadah lebih lama untuk menurunkan TBS setiap pohonnya, TBS tanaman yang sudah tinggi memiliki bobot yang lebih berat dibandingkan tanaman rendah hal ini memperberat cara kerja pemanenan. Menurut Mentari dkk (2012) dalam penelitian dengan judul "Hubungan Karakteristik Pekerja dan Cara Kerja dengan Kelelahan Kerja pada Pemanen Kelapa Sawit di PT. Perkebunan Nusantara IV (Persero) Unit Usaha Adolina Tahun 2012" kelelahan berhubungan dengan cara kerja khususnya memotong TBS dan pelepah. Kesulitan lain dalam kegiatan pemanenan kelapa sawit adalah saat pemanen yang memanen pohon kelapa sawit yang cukup tinggi. Pemanen harus memindahkan galah egrek dari satu pohon ke pohon lain. Pemanen harus mempertahankan galah egrek agar tidak jatuh dan sampai ke pohon lain dengan tepat agar tidak harus kembali menaikkan egrek dari bawah. Cara kerja menengadah 
ditambah dengan berat peralatan kerja akan mempengaruhi beban kerja. Beban kerja yang berat menjadi pemicu utama terjadinya kelelahan. Sehingga dapat dikatakan semakin tinggi pohon kelapa sawit maka semakin besar kelelahn pekerja pemanenan kelapa sawit.

Hal ini sejalan dengan penelitian Ihsan dan Indah (2015) dengan judul "Hubungan antara Bahaya Fisik Lingkungan Kerja dan Beban Kerja dengan Tingkat Kelelahan pada Pekerja di Divisi Stamping PT. X Indonesia" yang menghasilkan bahwa ada hubungan yang signifikan antara kelelahan kerja dengan beban kerja namun bertentangan dengan penelitian Nugroho dkk (2013) dengan judul "Hubungan antara Beban Kerja dengan Tingkat Kelelahan pada Petani di Desa Curut Kecamatan Penawangan Kabupaten Grobogan Tahun 2013" yang menyimpulkan bahwa tidak ada hubungan antara beban kerja dengan tingkat kelelahan kerja petani.

Persamaan regresi linier untuk hubungan antara faktor tinggi pohon dengan kelelahan pekerja adalah $\hat{Y}_{1}=$ $0,307+0,408 \mathrm{X}_{2}$.

\section{Hubungan antara Topografi Lahan dan Tinggi Pohon dengan Kelelahan Pekerja}

Hasil analisis korelasi ganda dan regresi linier berganda hubungan antara topografi lahan dan tinggi pohon dengan kelelahan pekerja dapat dilihat pada Tabel 6 dan Tabel 7 :

Tabel 6. Hasil Analisis Korelasi Hubungan antara Topografi lahan dan Tinggi Pohon dengan Kelelahan Pekerja

\begin{tabular}{ccc}
\hline \multicolumn{2}{c}{ Nilai } & Keterangan \\
\hline $\mathrm{Rx}_{1} \mathrm{x}_{2} \mathrm{y}$ & 0,598 & Korelasi cukup kuat \\
$\mathrm{F}_{\text {hitung }}$ & 17,163 & $\mathrm{~F}_{\text {hitung }}>\mathrm{F}_{\text {tabel, }}$ maka \\
$\mathrm{F}_{\text {tabel }}$ & 3,145 & $\mathrm{H}_{0}$ ditolak \\
\hline
\end{tabular}

Sumber : data diolah

Hubungan antara topografi lahan dan tinggi pohon dengan kelelahan pekerja mempunyai korelasi yang cukup kuat $(\mathrm{R}=$ 0,598). Sejalan dengan penelitian Ahmad dan Atun (2015) dengan judul "Beban Kerja dengan Kelelahan Kerja pada Pekerja
Industri Keripik Melinjo di Desa Benda Indaramayu" yang menghasilkan hubungan yang kuat antara beban kerja dengan kelelahan kerja pada pekerja industri Keripik Melinjo di Desa Benda Kecamatan Karangampel Kabupaten Indramayu tahun 2015.

Tabel 7. Hasil Analisis Regresi Linier Hubungan antara Topografi Lahan dan Tinggi Pohon dengan Kelelahan Pekerja

\begin{tabular}{ccc}
\hline \multicolumn{2}{c}{ Nilai } & Persamaan \\
\hline$\alpha$ & $-1,383$ & $\hat{Y}_{1}=-1,383+0,104 \mathrm{X}_{1}$ \\
$\beta_{1}$ & 0,104 & $+0,466 \mathrm{X}_{2}$ \\
$\beta_{2}$ & 0,466 & \\
\hline
\end{tabular}

Sumber : data diolah

Fhitung pada tabel hasil analisis korelasi adalah sebesar 17,163. Dimana nilai ini lebih besar dari nilai $F_{\text {tabel }}(3,145)$ yang berarti terdapat hubungan yang signifikan antara topografi lahan dan tinggi pohon dengan kelelahan pekerja. Sebagaimana menurut Nurjannah (2014) terdapat hubungan yang signifikan antara beban kerja dengan kelelahan kerja.

Topografi lahan dan tinggi pohon merupakan bagian dari lingkungan pekerja pemanenan kelapa sawit. Kesulitan pemanenan akan sangat bergantung pada kondisi lingkungan kerja pemanenan kelapa sawit. Kegiatan pemanenan yang memiliki kesulitan paling kecil adalah pemanenan di lahan datar (kemiringan $<8^{0}$ ) dengan tinggi pohon 2-6 meter. Pemanen tidak membutuhkan waktu yang lama untuk mempertimbangkan posisi berdiri saat memanen, selain itu peralatan yang digunakan hanya berupa dodos dan egrek dengan 1 batang galah. Sehingga kelelahan pekerja panen di lahan datar (kemiringan < $8^{0}$ ) dengan tinggi pohon 2-6 meter cukup rendah. Pemanen yang melakukan kegiatan panen di lahan datar (kemiringan $<8^{0}$ ) akan sangat mudah dalam mengumpulkan TBS hasil panen. Kegiatan pemanenan yang memiliki kesulitan paling besar adalah pemanenan di lahan sangat miring (kemiringan $>14^{0}$ ) dengan tinggi pohon 
10-12 meter. Pemanen membutuhkan waktu yang lama untuk mempertimbangkan posisi berdiri saat memanen, menaikkan galah egrek serta posisi kemungkinan jatuhnya TBS dan pelepah kelapa sawit. Selain itu peralatan yang digunakan cukup berat yaitu egrek dengan 2 batang galah. Sehingga kelelahan pekerja panen di lahan sangat miring (kemiringan $>14^{0}$ ) dengan tinggi pohon 10-12 meter cukup tinggi. Pemanenan pada topografi permukaan tanah yang derajat kemiringannya kecil dengan tinggi pohon yang rendah waktu panen dan tenaga yang dikeluarkan lebih sedikit. Sementara pemanenan pada topografi permukaan tanah yang derajat kemiringannya besar dengan tinggi pohon yang tinggi waktu panen dan tenaga yang dikeluarkan lebih banyak. Semakin berat beban kerja (topografi permukaan tanah dan tinggi pohon) maka semakin meningkat tingkat kelelahan kerja.

Persamaan regresi untuk hubungan antara faktor topografi permukaan tanah dan tinggi pohon dengan kelelahan pekerja adalah $\widehat{Y}_{1}=-1,383+0,104 \mathrm{X}_{1}+0,466 \mathrm{X}_{2}$.

\section{Hubungan antara Kelelahan Pekerja dengan Produktivitas Kerja}

Hasil analisis korelasi sederhana dan regresi linier sederhana hubungan antara kelelahan pekerja dengan produktivitas dapat dilihat pada Tabel 8 dan tabel 9:

Tabel 8. Hasil Analisis Korelasi Hubungan antara Kelelahan Pekerja dengan Produktivitas

\begin{tabular}{ccc}
\hline \multicolumn{2}{c}{ Nilai } & Keterangan \\
\hline $\mathbf{r}$ & $-0,373$ & $\begin{array}{c}\text { Korelasi lemah dan } \\
\text { tidak searah }\end{array}$ \\
Signifikansi & $<0,05$ & $\mathrm{H}_{0}$ ditolak \\
\hline
\end{tabular}

Sumber : data diolah

Tabel 9. Hasil Analisis Regresi Linier Hubungan antara Kelelahan Pekerja dengan Produktivitas

\begin{tabular}{|c|c|c|}
\hline \multicolumn{2}{|c|}{ Nilai } & Persamaan \\
\hline$\alpha$ & 379,243 & $\hat{Y}_{2}=379,243-23,495$ \\
\hline$\beta$ & $-23,495$ & $\mathrm{Y}_{1}$ \\
\hline
\end{tabular}

Sumber : data diolah

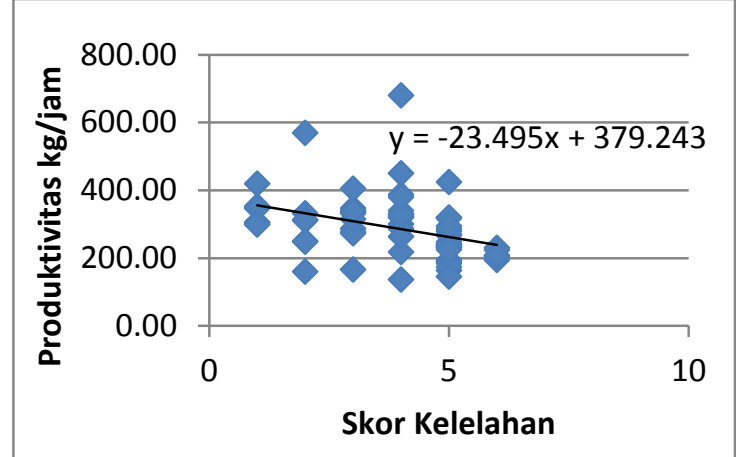

Gambar 3. Hubungan antara kelelahan kerja dengan produktivitas.

Hubungan antara kelelahan pekerja dengan produktivitas mempunyai korelasi yang lemah, karena nilai $r=(-) 0,373$ berada dalam interval $0,20-0,399$ (Sugiyono, 2010) . Hal ini berbeda dengan penelitian Roshadi (2014) dengan judul "Hubungan Kelelahan Kerja dengan Produktivitas Kerja Karyawan di Fakultas Dakwah dan Komunikasi Universitas UIN Sunan Kalijaga Yogyakarta” yang menunjukkan nilai koefisien korelasi sebesar 0,456 dan menyimpulkan bahwa terdapat hubungan yang cukup erat antara kelelahan kerja dengan produktivitas. Nilai $r$ pada tabel hasil analisis korelasi bernilai negatif maka diketahui bahwa hubungan antara kelelahan pekerja dengan produktivitas adalah tidak searah. Roshadi (2014) juga menunjukkan terdapat korelasi yang negatif (tidak searah) antara kelelahan kerja dengan produktivitas kerja. Hal ini berarti apabila skor kelelahan pekerja tinggi maka produktivitas akan rendah atau apabila skor kelelahan pekerja rendah, maka produktivitas akan tinggi.

Hubungan yang signifikan antara kelelahan pekerja dengan produktivitas dengan nilai signifikansi lebih kecil dari nilai probabilitas $(0,05)$.

Hal ini sejalan dengan penelitian Roshadi (2014) yang menyimpulkan bahwa terdapat hubungan yang signifikan antara kelelahan kerja dengan produktivitas kerja karyawan di Fakultas Dakwah dan Komunikasi Universitas UIN Sunan Kalijaga Yogyakarta. Selaras dengan penelitian Muizzudin (2013) dengan judul "Hubungan antara Kelelahan Kerja dengan 
Produtivitas Kerja pada Tenaga Kerja Bagian Tenun di PT. Alkatex Tegal" yang menyatakan bahwa terdapat hubungan antara kelelahan kerja dengan produktivitas kerja pada tenaga kerja bagian tenun di PT. Alkatex Tegal. Begitu pula dengan penelitian Elia, et al. (2016) dengan judul "Hubungan antara Kelelahan Kerja dan Masa Kerja dengan Produktivitas Kerja Pada Tenaga Kerja Bongkar Muat di Pelabuahan Bitung Tahun 2015" yang menyatakan bahwa terdapat hubungan antara kelelahan kerja dengan produktivitas kerja pada tenaga kerja bongkar muat di pelabuhan Bitung.

Dalam bekerja, harus dicari posisi yang sesuai agar tidak mudah lelah dan produktivitas dapat meningkat. Karena semakin tinggi kelelahan kerja fisik maka semakin dapat menurunkan produktivitas kerja. Bagi pekerja panen kelapa sawit, tentu diperlukan kesiapan fisik, mental, peralatan dan kondisi lingkungan kerja yang baik. Karena jika tidak, kelelahan dapat terjadi setiap saat dan dapat menggangu kinerja pekerja yang nantinya akan berpengaruh terhadap produktivitas pada perusahaan tersebut.

Persamaan regresi untuk hubungan antara kelelahan pekerja dengan produktivitas kerja adalah $\widehat{Y}_{2}=379,243$ 23,495 $\mathrm{Y}_{1}$.

\section{KESIMPULAN DAN SARAN}

\section{Kesimpulan}

Bedasarkan hasil penelitian dapat disimpulkan bahwa semakin tinggi topografi permukaan tanah (derajat kemiringan) maka semkin tinggi kelelahan pekerja dan begitu pula semakin tinggi pohon kelapa sawit maka semakin tinggi kelelahan pekerja. Kelelahan pekerja yang tinggi akhirnya bermuara kepada rendahnya produktivitas kerja.

\section{Saran}

Berdasarkan kesimpulan diharapkan adanya perbaikan sistem kerja pemanenan kelapa sawit dalam aspek lingkungan kerja dan peralatan panen yang dapat membantu pekerjaan panen sehingga dapat menurunkan kelelahan pekerja dan meningkatkan produktivitas. Inovasi peralatan panen sangat dibutuhkan agar permasalahan tinggi pohon kelapa sawit dapat diatasi karena hubungannya dengan kelelahan pekerja adalah cukup kuat sehingga produktivitas dapat ditingkatkan.

Saran kepada peneliti lain atau peneliti selanjutnya yaitu dapat melakukan penelitian sejenis namun dengan menambahkan variabel lain juga dapat mempengaruhi kelelahan pekerja dan produktivitas pemanen kelapa sawit.

\section{DAFTAR PUSTAKA}

Ahmad, S. dan Atun, A. 2015. Beban Kerja dengan Kelelahan Kerja pada Pekerja Industri Kripik Melinjo di Desa Benda Indramayu. Jurnal Kesehatan Masyarakat. 1 (3) : 25-30.

BPS Provinsi Bengkulu, 2016. Bengkulu Dalam Angka 2016. Badan Pusat Statistik Provinsi Bengkulu.

Budi. 2006. SPSS 13.0 Terapan; Riset Statistik Parametrik. Yogyakarta : Penerbit ANDI.

Chesnal, H., A.J.M. Rattu dan B.S. Lampus. 2014. 2014. Hubungan Antara Umur, Jenis Kelamin, dan Status Gizi dengan Kelelahan pada Tenaga Kerja di Bagian Produksi PT. Putra Karangetang Popontolen Minahasa Selatan. Skripsi. Fakultas Kesehatan Masyarakat, Universitas Sam Ratulangi.

Elia, K.P., Johan, J. dan Ardiansa, T. T. 2016. Hubungan antara Kelelahan Kerja dan Masa Kerja dengan Produktivitas Kerja Pada Tenaga Kerja Bongkar Muat di Pelabuahan Bitung Tahun 2015. Jurnal Ilmiah Farmasi. 5 (2) : 107-113. 
Ihsan, T. dan Indah, R.S.S. 2015. Hubungan antara Bahaya Fisik Lingkungan Kerja dan Beban Kerja dengan Tingkat Kelelahan di Divisi Stamping PT. X Indonesia. Jurnal Teknik Lingkungan UNAND. 12 (1) : 10-16.

Mentari, A. Kalsum dan Umi, S. 2012. Hubungan Karakteristik Pekerja dan Cara Kerja dengan Kelelahan Kerja pada Pemanen Kelapa Sawit di PT. Perkebunan Nusantara IV (PERSERO) Unit Usaha Adolina Tahun 2012. Jurnal Lingkungan dan Kesehatan Kerja. 1 (2).

Mimboro, P., et al. 2015. Pengembangan Kriteria Kesesuaian Lahan Kelapa Sawit (Elaeis Guineensis Jacq) di Perkebunan Nusantara-II, Sumatera Utara. Jurnal Penelitian Kelapa Sawit. 23 (1) : 16-26.

Muizzuddin, A. 2013. Hubungan Antara Kelelahan Kerja Dengan Produktivitas Kerja Pada Tenaga Kerja Bagian Tenun Di Pt. Alkatex Tegal. Skripsi. Fakultas Ilmu Keolahragaan, Universitas Negeri Semarang.

Nainggolan, R., Agus P dan Yuliarso, M.Z. Faktor-Faktor Yang Mempengaruhi Produktivitas Tenaga Kerja Pemanen Sawit Pada PT. Bio Nusantara Teknologi. Jurnal AGRISEP. 11 (1) : 35-42.

Nugroho, A., Catur, Y. dan Eko, H. 2013. Hubungan antara Beban Kerja dengan Tingkat Kelelahan pada Petani di Desa Curut Kecamatan Penawangan Kabupaten Grobogan Tahun 2013. Skripsi. Fakultas Kesehatan Universitas Dian Nuswantoro.

Nurjannah. 2014. Hubungan antara Beban Kerja dengan Kelelahan Kerja pada Karyawan Bagian Cutting PT. Dan
Liris Banaran Kabupaten Sukoharjo. Skripsi. Program Studi Kesehatan Masyarakat. Fakultas Ilmu Kesehatan. Univerisitas Muhammadiyah Surakarta. Nurzam, Alexander, H., Ujang, R. Dan Osdimen, S.G. 2014. Petunjuk Tekhnis Perkebunan Kelapa Sawit. PT.Bio Nusantara Teknologi Bengkulu. Buku tidak diterbitkan.

Oesman, T.I. dan Risma, A.S. 2011. Hubungan Faktor Internal dan Eksternal Terhadap Kelelahan Kerja Melalui Subjective Self Rating Test. Procceding 11th national Conference of Indonesian Ergonomics Society. Depok, 14-15 September 2011.

Putranti, K.A., Sam H dan M.Faiz S. 2012. Studi Waktu (Time Study) pada Aktivitas Pemanenan Kelapa Sawit Di Perkebunan Sari Lembah Subur, Riau. Jurnal Keteknikan Pertanian. 26 (2) : 99-106.

Riduwan. 2011. Dasar-dasar Statistika. Bandung : Alfabeta.

Roshadi, I. 2014. Hubungan Kelelahan Kerja dengan Produktivitas Kerja Karyawan di Fakultas Dakwah dan Komunikasi Universitas UIN Sunan Kalijaga Yogyakarta. Skripsi. Jurusan Manajemen Dakwah. Fakultas Dakwah dan Komunikasi. Universitas Islam Negeri Sunan Kalijaga Yogyakarta.

Santosa, T.N.B. dan Andreas W.K. 2014. Pengaruh Topografi Lahan dan Umur Pemanen Terhadap Kapasitas Kerja Pemanenan Kelapa Sawit. Dari :http://www.slideshare.net/andreaskri sdiarto/tri-andrepengaruh-topograf-numur Diakses 08 September 2016 20.49 WIB.

Sugiyono. 2010. Metode Penelitian Kuantitatif, Kualitatif, dan $R \& D$. Bandung : Alfabeta. 
Tarwaka, Solichul, B., Lilik S. 2004. Ergonomi Untuk Keselamatan,
Kesehatan Kerja dan Produktivitas. Surakarta : UNIBA Press. 